\title{
Investigation of the presence of NDM-1, VIM-1 and OXA-1 genes in MDR strains of Klebsiella pneumoniae isolated from clinical specimens
}

Melika Taleb

Islamic Azad University Tehran North Branch

Farzaneh Hosseini ( $\square$ hosseinif148@gmail.com )

Islamic Azad University Tehran North Branch

Research article

Keywords: OXA-1, NDM-1, VIM-1, Klebsiella pneumoniae, Beta-lactamase

Posted Date: September 27th, 2019

DOI: https://doi.org/10.21203/rs.2.15319/v1

License: (c) (1) This work is licensed under a Creative Commons Attribution 4.0 International License.

Read Full License 


\section{Abstract}

Background:

Klebsiella pneumoniae has emerged as a significant opportunistic pathogen responsible for nosocomial infections. This bacteria is frequently resistant to multiple classes of antibiotics such as the family of beta-lactam antibiotics. The aim of this study was the molecular evaluation of resistant strains of Klebsiella pneumonia isolation of multiple resistant drugs from clinical specimens.

Methods:

60 clinical isolates of Klebsiella pneumoniae were isolated and identified by staining and biochemical tests during fall season from a laboratory in Tehran. Antimicrobial susceptibility testing was carried out using a disk diffusion method with CLSI standards. All isolates were examined by PCR test for the presence of NDM-1, VIM-1, and OXA-1 genes.

Results:

The highest resistance in the strains was related to antibiotic ampicillin (90\%), followed by the highest resistance to ciprofloxacin (70\%), cefixime (66.66\%), trimethoprim-sulfamethoxazole (65\%), piperacillin (50\%). Also, most susceptibilities were to ampicillin antibiotics (85\%), gentamicin (70\%), piperacillintazobactam (60\%) and amikacin (56.66\%). Out of the 60 isolated strains, 3 isolates (5\%) had the VIM-1 enzyme gene, 2 isolates (3.3\%) had the OXA-1 enzyme gene and no isolates were found with the NDM-1 enzyme gene.

Conclusion:

The high levels of antibiotic resistance among the organisms that cause clinical infections suggest that the mechanisms involved in the development of resistance and the evaluation of antimicrobial activity of new drugs in vitro can help the process of effective treatment of these infections.

\section{Background}

Klebsiella is one of the five most common gram-negative bacteria in hospital infections, which accounted for between 7\% and 10\% of hospital sepsis between 1997 and 2002 [1]. Among the species of Klebsiella, Klebsiella pneumoniae is the most common, accounting for $75-86 \%$ of the reported Klebsiella. Klebsiella pneumoniae species sometimes appear as severe pneumonia and through acquired infections from the community [2, 3]. These strains are widely colonized in hospitals. Sepsis that cause Klebsiella pneumoniae is commonly seen in patients who are infected with urinary tract ulcers [4]. The severity of sepsis is so severe that some patients die from infection severely. The colonization of the respiratory tract is very common, but it is very difficult to evaluate and diagnose patients with severe disease. Even in some cases, Klebsiella predominates as an infectious agent [5]. 
The emergence of bacterial resistance is not only about Klebsiella but also about all bacteria today. Especially, with the advent of Klebsiella pneumoniae that can hydrolyze cephalosporins and even carbapenems, the scientific community has been very cautious about the therapeutic approach. OXA beta-lactamases are resistant to ampicillin and cephalothin, and their high hydrolytic activity is against oxacillin and cloxacillin and poor inhibition by clavulanic acid. The OXA $\beta$-lactamase family includes a number of $\beta$-lactamases that have a particular hydrolysis profile, so the members of the family have a similarity of $20 \%$ and a low sequence, but with regard to new cases added to this family it is known that between one or Several members of the OXA $\beta$-Lactamase family have some similarity $[6,7]$.

$A, C$, and D classes of the Ambler classification contains beta-lactamases that are serine on their active site, while class $B$ beta-lactamases are all metalloenzymes that require zinc for their catalytic activity and are said to be metallo-lactamase [8-10]. The NDM-1 gene (New Delhi, metallo- $\beta$-lactamase 1 ) is a carbapenem are hydrolyzed that all of the $\beta$-lactams, except monobactams, and sensitive to EDTA, but not sensitive to clavulanic acid. The NDM-1 gene is usually transmitted by conjugation [11]. This betalactamase is in Class B of the Ambler classification. Metallo-lactamases (MBLs) has a variety of IMP and VIM and is potentially clinically important. These enzymes are active against most $\beta$-lactams, including carbapenems, and have been found in various gram-negative clinical isolates in most regions of the Far East and the Mediterranean. Among the Klebsiella pneumoniae, the VIM group, and in particular VIM-1, are dominant. BlaVIM genes are in class 1 of the introns and are identified in plasmids with different types of the replicon. Epidemiological studies have shown that in order to control the release of bacterial resistance in a geographic region, it is necessary to obtain information on susceptibility patterns of bacteria in that area [12]. Therefore, the purpose of this study was to investigate the molecular properties of resistant strains of Klebsiella pneumoniae isolated from multi-drug resistant clinical specimens.

\section{Methods}

Samples were collected from medical diagnostic laboratories in the city of Tehran (all available samples) during the autumn of the year 1396 and samples were transferred to the laboratory quickly. The consent form was signed by all patients.

\section{Isolation and identification of strains}

First, the collected samples were enriched by microbiological methods. At first, each sample was cultured on an EMB medium and Blood Agar. In the next step, Klebsiella pneumoniae isolates were identified via common biochemical methods and then stored in 30\% glycerol at - 20هC in Trypticase Soy Broth (TSB) involved for more study.

\section{Antibiotic susceptibility test}

The antibiotic susceptibility testing was conducted with disk diffusion method (Kirby-Bauer) according to CLSI recommendation using 11 antibiotics from the Mast company (United Kingdom), including 
amikacin, gentamicin, ciprofloxacin, trimethoprim-sulfamethoxazole, ceftazidime, imipenem, cefepime, cefixime, ampicillin, piperacillin, and piperacillin-tazobactam are used.

\section{DNA extraction (Yekta-Tajhiz Azma kit)}

1. A bacterial colony was prepared in distilled water microbial suspension was prepared and the centrifuge with $14000 \mathrm{rpm}$ and the supernatant was out.

2. Add $200 \mu$ of FATG1 buffer and mix well.

3. $200 \mu \mathrm{l}$ of Proteinase $\mathrm{K}(10 \mathrm{mg} / \mathrm{ml})$ was added to the mixture and then vertex.

4. At $60^{\circ} \mathrm{C}$, it was incubated for 1 hour until it was completely lysed. During the incubation, vortexed for 15 minutes and spin for a few seconds.

5. $200 \mu \mathrm{l}$ of FATG2 buffer was added to the mixture and then vortexed and completely mixed and incubated for 10 minutes at $70^{\circ} \mathrm{C}$ and spin for a few seconds.

6. $200 \mu \mathrm{l}$ of ethanol was added to the sample and then vortexed. Spin for a few seconds.

7. The mixture was poured into a column and then centrifuged at $1 \mathrm{rpm}$ at $5000 \mathrm{rpm}$.

8. $400 \mu \mathrm{l}$ of W1 Buffer was added to the column and centrifuged at $14000 \mathrm{rpm}$ for 1 minute and the supernatant was out.

9. A $750 \mu \mathrm{l}$ Wash Buffer was added to the column and centrifuged for 1 minute at about $14000 \mathrm{rpm}$ and the liquid was discarded. Then, again, centrifuge for 3 minutes at about 14,000 rpm to dry the column. Then the column was laid inside the Elution Tube.

10. The $30 \mathrm{ml}$ of Elution Buffer was poured into the column at room temperature and then centrifuged at $14000 \mathrm{rpm}$. Finally, the gel was electrophoresed to test the quality of extraction.

Detection of VIM-1, OXA-1, and NDM-1 genes

The PCR was performed with Bio-Rad thermal cycler T100. Primers and temperature conditions used in this study are listed in Table 1.

The statistical analysis

For statistical analysis and comparison of the results, the SPSS-18 software was used. Statistical analysis was also performed using Excel 2010 statistical software to further analyze the data.

Furthermore, qualitative data were analyzed using $\chi 2$ (Chi-Square test) and Fisher-Mann-Whitney U-test. Variables with $P$ value $<0.5$ were significant in the analysis.

\section{Results}

\section{Sampling}

In this study, 60 strains of Klebsiella pneumoniae were identified by differential sets. 
The percentage of antibiotic resistance in the strains studied is shown in diagram 1.

Investigating the presence of metallo-beta-lactamase and carbapenemase genes of VIM-1,NDM-1, and OXA-1

Investigation of carbapenemase genes of $V I M-1, N D M-1$ and $O X A-1$ in Klebsiella pneumoniae isolated from clinical specimens using PCR. Of the 60 isolated isolates, 3 isolates (5\%) were tested with the VIM1 enzyme gene. In Figure 1, the PCR reaction for the VIM-1 beta-lactamase gene is shown. No isolate was found for the NDM-1 enzyme gene. In Figure 2, the PCR reaction is shown for the NDM-1 betalactamase gene. 2 isolates (3.3\%) also had the enzyme gene OXA-1. In Figure 3 , the PCR reaction is shown for the beta-lactamase OXA-1 gene.

Statistical analysis of data

Determination of the relationship between the presence of the studied genes and the resistance to each of the antibiotics examined by SPSS v23 and Fisher test. Genes and antibiotics were analyzed, respectively, below their $p$-value. The NDM-1 gene was not found in this study, so it is not included in this analysis.

Based on the results in this table, it was revealed that the presence of both $V I M-1$ and $O X A-1$ genes with resistance to antibiotics at 0.05 was not significant. However, the presence of the VIM-1 gene with resistance to antibiotic cefepime at the level of 0.09 was significant, because all three strains that had $V I M-1$ gene were also resistant to cefepime.

\section{Discussion}

In this study, 60 strains of Klebsiella pneumoniae were identified by differential tests. The results showed that the highest resistance to antibiotics was ampicillin (90\%). After that, the highest resistance was related to ciprofloxacin (70\%), cefixime (66.66\%), trimethoprim-sulfamethoxazole (65\%), and piperacillin $(50 \%)$. Also, most susceptibilities were to imipenem antibiotics (85\%), gentamicin (70\%), piperacillintazobactam (60\%) and amikacin (56.66\%). Based on the results, it was found that the presence of both $V I M-1$ and $O X A-1$ genes was not significantly correlated with resistance to antibiotics. However, the presence of the VIM-1 gene with resistance to antibiotic cefepime at the level of 0.9 was significant, because all three strains that had $V I M-1$ gene were also resistant to cefepime.

According to other studies, it is noteworthy that all ESBL-producing organisms are remarkably sensitive to carbapenems. There are numerous studies and reports about the increasing prevalence of ESBL producing organisms from different regions of the country. The increase in the prevalence of ESBL producing organisms is causing concern. Carbapenems are considered as suitable pharmaceutical agents for the treatment of infections caused by Gram-negative bacteria with multi-drug resistance. Fortunately, resistance to Carbapenems in the country is low among Enterobacteriaceae family members 
and successful treatment of various infections using these agents is reported at the clinic. Also, based on the results of our study, it can be suggested that antibiotics such as amikacin and gentamicin, in addition to antibiotics of carbapenems, can be used to treat infections caused by these organisms useful in the clinic. Recently, Alikhani et al study in Iran showed that $75 \%$ susceptibility to carbapenems is among ESBL producing pathogens [13].

One of the important findings of Sadegh Rezaei et al. in 2015 was that they found high sensitivity to extended-spectrum antibiotics such as carbapenems in E. coli strains, which contrasted with other studies that show less sensitivity (about 34\%) to imipenem and meropenem in India, Malaysia, and Saudi Arabia. In the present study, high sensitivity to imipenem (85\%) was observed, which is similar to that of Rezaei et al [14].

Jamal et al. conducted a study in Kuwait in 2016, in which a total of 764 isolates of Enterobacteriaceae were used. Of these, $7.98 \%$ were resistant to carbapenem and $34.4 \%$ were NDM-1 producers. All patients with NDM-1 positive bacteria are admitted to the hospital. There is a clear difference between the two studies. In the present study, no strain containing the $N D M-1$ gene was found. This difference can be due to several factors such as differences in the geographical area under study, differences in the type of bacteria and strains examined, public health and individual in the geographical area and excessive use of antibiotics in that area is under investigation. In the present study, the resistance to carbapenems remains at a low level. The results of the study of Jamal also related to carbapenem resistance to this result. Shows that can be used in different geographical areas of carbapenem as a suitable drug for the treatment of these bacteria [15].

In the study of Sugumar et al. In 2014, the $O X A-1$ gene detected in Klebsiella pneumonia strains. In this study, 151 strains of Klebsiella pneumoniae were isolated and identified. The OXA-1 gene was detected in 12 strains of these samples (94.9\%). In the current study, the prevalence of the OXA-1 gene was 3.3\%. The prevalence of this gene in their study was more than twice the current study [16]. As it has been said, studying in different geographical regions can have a different pattern of resistance prevalence or genes. Therefore, the reason for these differences is as mentioned: 1 . Different geographic regions 2. Differences in public health and individual 3. Different patterns in the use of antibiotics [17-19].

\section{Conclusion}

A high level of antibiotic resistance among the organisms causing clinical infections suggests that the mechanisms involved in the development of resistance and the evaluation of antimicrobial activity of new drugs in vitro can help the process of effective treatment of these infections. Also, after statistical analysis, there was no significant relationship between the presence of genes and the resistance to common antibiotics. But there may be a relationship between the presence of these genes and other antibiotics.

\section{Abbreviations}


NDM-1: New Delhi metallo-beta-lactamase 1, VIM-1: Verona integron-encoded metallo- $\beta$-lactamase) (Class B),OXA-1: oxacillinase group of $\beta$-lactamases (Class D), MBLs: Metallo-lactamases, TSB:

Trypticase Soy Broth.

\section{Declarations}

Ethics approval: Data for this study consisted of anonymized laboratory results devoid of individual patient information or identifiers hence ethical approval and individual informed consent were not necessary.

Consent for publication: Permission to publish the compiled data was obtained from participating laboratories.

Availability of data and material: The datasets used and analyzed during the current study are available from the corresponding author on reasonable request.

Competing interests: The authors declare that they have no competing interest.

Funding: This research is not supported by a specific project grant.

Authors' contributions: Melika Taleb: Investigate and supervised the findings of this work, wrote the article. Developed the theoretical framework, Farzaneh Hosseini: Designed the study, helped supervise the project, and conceived the original idea. Designed the model and the computational framework and analyzed the data. Discussed the results and commented on the manuscript.

Acknowledgements: Department of Microbiology, Islamic Azad University, Tehran North Branch, Tehran, Iran.

\section{References}

1.Peleg, A. Y. and D.C. Hooper, Hospital-acquired infections due to gram-negative bacteria. The New England journal of medicine, 2010. 362(19): p. 1804-1813.

2.Ghasemian, A., et al., Molecular Typing of Klebsiella pneumoniae isolates using Repetitive Extragenic Palindromic Sequence-Based PCR in a Hospital in Tehran, Iran. Int J Enteric Pathog, 2018. 6(1): p. 27-30.

3.ESLAMI, M., et al., IDENTIFICATION OF CTX-M, SHV AND TEM PRODUCING KLEBSIELLA PNEUMONIAE WITH USING OF REP-PCR TYPING ASSAY. 2017.

4.Peerayeh, S. N., et al., High frequency of extended-spectrum $\beta$-lactamase-producing Klebsiella pneumoniae and Escherichia coli isolates from male patients' Urine. Archives of Clinical Infectious Diseases, 2016. 11(2). 
5.Peleg, A. Y. and D.C. Hooper, Hospital-acquired infections due to gram-negative bacteria. New England Journal of Medicine, 2010. 362(19): p. 1804-1813.

6.Yigit, $\mathrm{H}$., et al., Novel carbapenem-hydrolyzing $\beta$-lactamase, $K P C-1$, from a carbapenem-resistant strain of Klebsiella pneumoniae. Antimicrobial agents and chemotherapy, 2001. 45(4): p. 1151-1161.

7.Naas, T., et al., Plasmid-mediated carbapenem-hydrolyzing $\beta$-lactamase KPC in a Klebsiella pneumoniae isolate from France. Antimicrobial agents and chemotherapy, 2005. 49(10): p. 4423-4424.

8.Najar Peerayeh, S., et al., High prevalence of blaCTX-M-1 group extended-spectrum $\beta$-lactamase genes in Escherichia coli isolates from Tehran. Jundishapur Journal of Microbiology, 2013. 6(7): p. 1-6.

9.Bush, K., G. A. Jacoby, and A. A. Medeiros, A functional classification scheme for beta-lactamases and its correlation with molecular structure. Antimicrobial agents and chemotherapy, 1995. 39(6): p. 1211.

10.Eslami, M. and P. S. NAJAR, Phenotypic and molecular detection of TEM, PER, and VEB betalactamases in clinical strains of Escherichia coli. 2012.

11.Yong, D., et al., Characterization of a new metallo- $\beta$-lactamase gene, blaNDM-1, and a novel erythromycin esterase gene carried on a unique genetic structure in Klebsiella pneumoniae sequence type 14 from India. Antimicrobial agents and chemotherapy, 2009. 53(12): p. 5046-5054.

12.Zhao, W.-H. and Z.-Q. Hu, Epidemiology and genetics of VIM-type metallo- $\beta$-lactamases in Gramnegative bacilli. Future microbiology, 2011. 6(3): p. 317-333.

13.Safari, M., et al., High prevalence of multidrug resistance and metallo-beta-lactamase (M $\beta L$ ) producing Acinetobacter baumannii isolated from patients in ICU wards, Hamadan, Iran. Journal of research in health sciences, 2013. 13(2): p. 162-167.

14.Rezai, M. S., et al., Characterization of multidrug resistant extended-spectrum beta-lactamaseproducing Escherichia coli among uropathogens of pediatrics in North of Iran. BioMed research international, 2015. 2015.

15.Jamal, W. Y., M. J. Albert, and V. O. Rotimi, High prevalence of new delhi metallo- $\beta$-lactamase-1 (NDM-1) producers among carbapenem-resistant Enterobacteriaceae in Kuwait. PloS one, 2016. 11(3): $\mathrm{p}$. e0152638.

16.Sugumar, M., et al., Detection of OXA-1 $\beta$-lactamase gene of Klebsiella pneumoniae from blood stream infections (BSI) by conventional PCR and in-silico analysis to understand the mechanism of OXA mediated resistance. PloS one, 2014. 9(3): p. e91800.

17.Coque, T., F. Baquero, and R. Canton, Increasing prevalence of ESBL-producing Enterobacteriaceae in Europe. Eurosurveillance, 2008. 13(47): p. 19044. 
18.Villegas, M., et al., Prevalence of extended-spectrum $\beta$-lactamases in South America. Clinical Microbiology and Infection, 2008. 14: p. 154-158.

19.Canton, R., et al., Prevalence and spread of extended-spectrum $\beta$-lactamase-producing Enterobacteriaceae in Europe. Clinical Microbiology and infection, 2008. 14: p. 144-153.

\section{Tables}

Table 1. The primers used for the detection of bla genes and the amplicon size of this gene.

\begin{tabular}{|c|c|c|c|c|}
\hline Primer & Product & Sequence $(5 \phi$ to $3 \phi)$ & Annealing $\mathrm{T}$, time & $\operatorname{Tm}$ \\
\hline$V I M-1(F)$ & \multirow{2}{*}{$503 \mathrm{bp}$} & TGA GTA TCC GAC AGT CAA C & \multirow{2}{*}{$55^{\circ} \mathrm{C}, 1 \mathrm{~min}$} & $53^{\circ} \mathrm{C}$ \\
\hline$V I M-1(R)$ & & CAC AAC CAC CGT ATA GCA & & $52^{\circ} \mathrm{C}$ \\
\hline$O X A-1(F)$ & \multirow[t]{2}{*}{$392 \mathrm{bp}$} & GAA CAG CAA TCA TAC ACC AA & \multirow[t]{2}{*}{$54^{\circ} \mathrm{C}, 1 \mathrm{~min}$} & $53^{\circ} \mathrm{C}$ \\
\hline$O X A-1(R)$ & & TAA TAA ACC CTT CAA ACC ATC C & & $52^{\circ} \mathrm{C}$ \\
\hline$N D M-1(F)$ & \multirow[t]{2}{*}{$258 \mathrm{bp}$} & GCA GCA CAC TTC CTA TCT & \multirow[t]{2}{*}{$52^{\circ} \mathrm{C}, 1 \mathrm{~min}$} & $54^{\circ} \mathrm{C}$ \\
\hline$N D M-1(R)$ & & GAC AAC GCA TTG GCA TAA & & $52^{\circ} \mathrm{C}$ \\
\hline
\end{tabular}

Table 2: P-value of VIM-1 and OXA-1 genes in relation to resistance to antibiotics

\begin{tabular}{|l|l|l|}
\hline Antibiotics & VIM-1 & OXA-1 \\
\hline ciprofloxacin & 0.665 & 0.514 \\
\hline ceftazidime & 0.209 & 0.356 \\
\hline imipenem & 0.391 & 0.280 \\
\hline cefepime & 0.076 & 0.184 \\
\hline cefixime & 0.289 & 0.441 \\
\hline ampicillin & 0.725 & 0.808 \\
\hline trimethoprim-sulfamethoxazole & 0.267 & 0.419 \\
\hline amikacin & 0.175 & 0.317 \\
\hline gentamicin & 0.335 & 0.486 \\
\hline piperacillin & 0.247 & 0.397 \\
\hline piperacillin-tazobactam & 0.650 & 0.356 \\
\hline
\end{tabular}

\section{Figures}




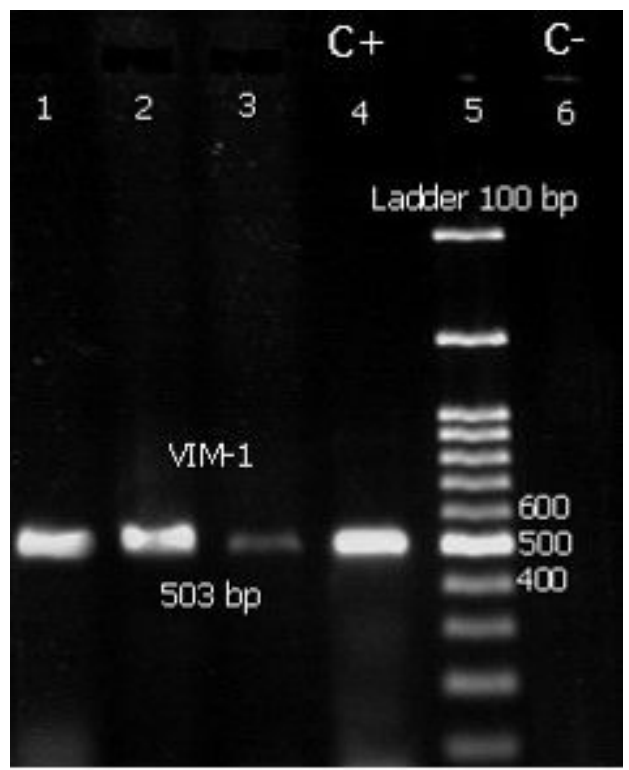

\section{Figure 1}

PCR product electrophoresis for the VIM-1 gene. Wells No. 1, 2, and 3 were positive clinical isolates with a size of 503 bp, well No. 4 positive control $(\mathrm{C}+)$ having the VIM-1 gene, Ladder $100 \mathrm{bp}$ well number 5 , and negative control well No. 6 (C-)

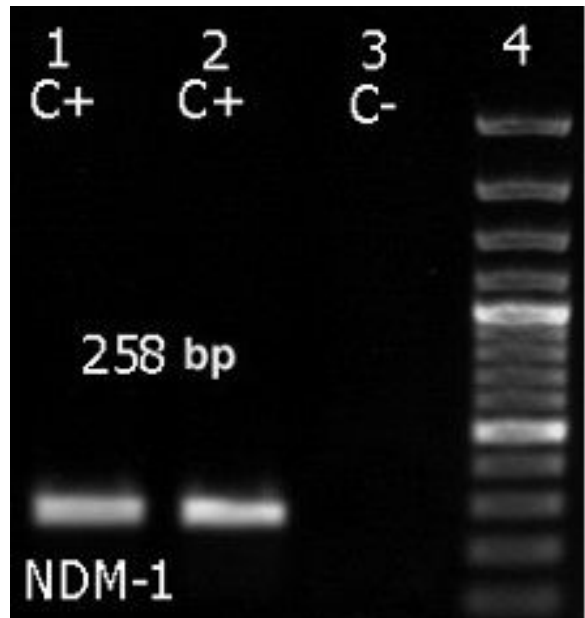

ladder 100bp

Figure 2

PCR product electrophoresis for the NDM-1 gene. Wells No. 1 and 2 have a positive control $(C+)$ of 258 bp with NDM-1 gene, negative control well (C-) and wellhead No. 4, bp 100 ladder. 


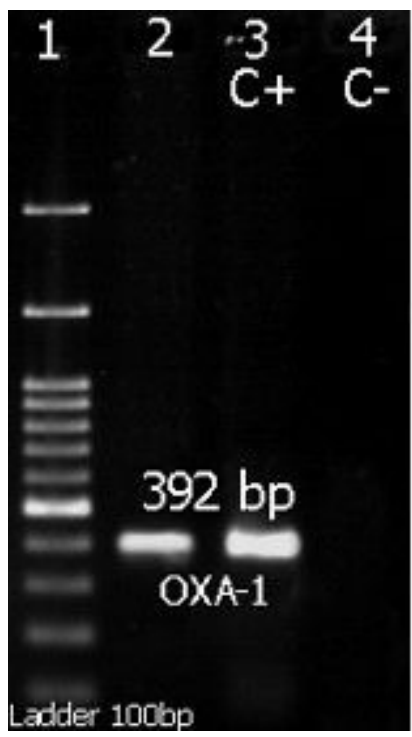

\section{Figure 3}

PCR product electrophoresis for the OXA-1 gene. Wells No. 1, 100 ppm bp, No. 1, Clinical specimen of OXA-1 gene with a size of $392 \mathrm{bp}$, well No. 3 positive control $(\mathrm{C}+)$ with a size of $392 \mathrm{bp}$ and negative control well No. 4 (C-).

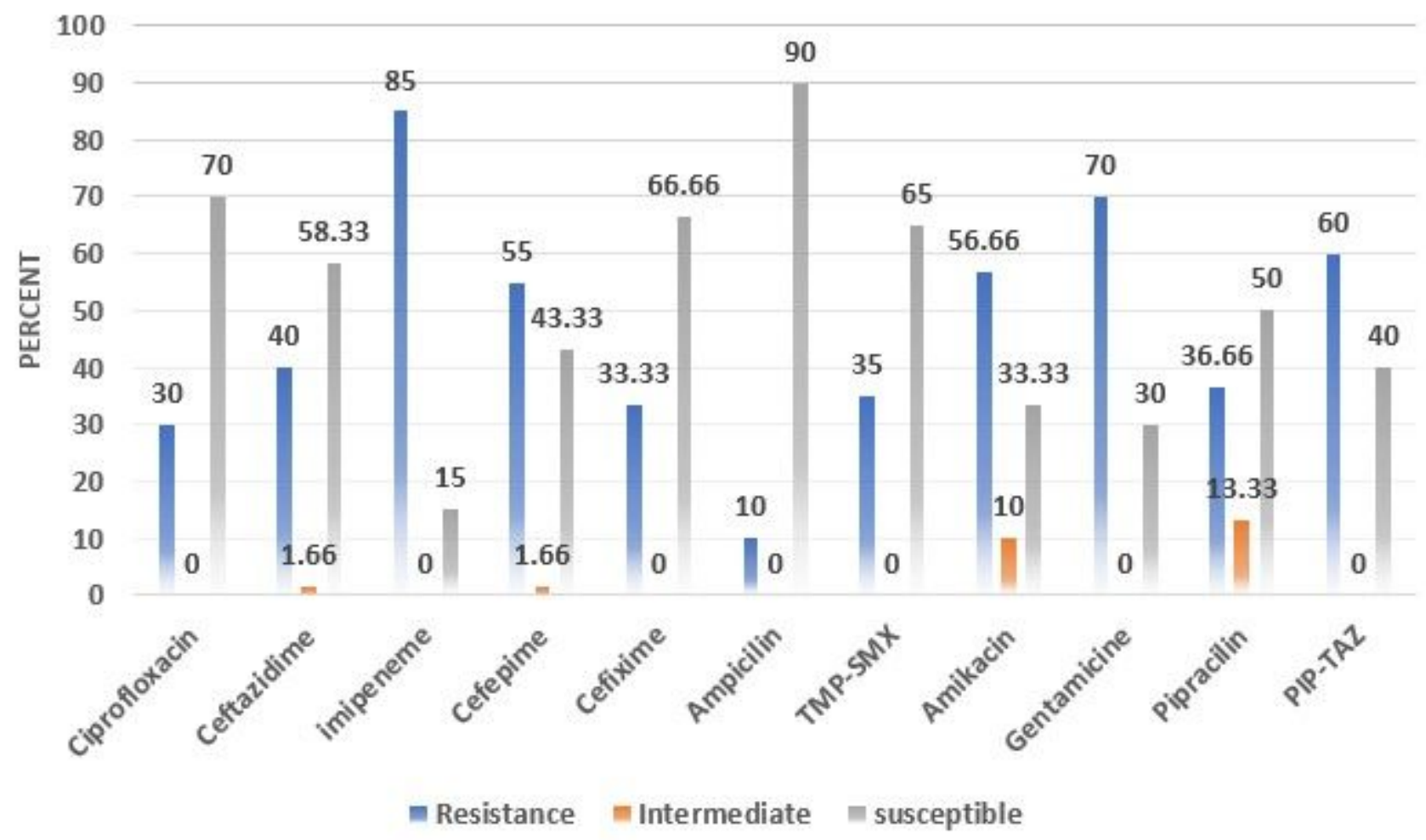

Figure 4

Diagram 1. The frequency of antibiotic resistance in the strains. 